\title{
Effects of $\mathrm{BCcl}$ nanoparticle and its mixture with doxorubicin on survival of murine 4TI tumor model
}

This article was published in the following Dove Press journal: OncoTargets and Therapy

\author{
Maryam Hafizi ${ }^{1,2}$ \\ Masoud Soleimani ${ }^{3}$ \\ Sajad Noorian ${ }^{4}$ \\ Somayeh Kalanaky ${ }^{2}$ \\ Saideh Fakharzadeh ${ }^{2}$ \\ Nafiseh Tavakolpoor Saleh ${ }^{5}$ \\ Mohammad Hassan Nazaran ${ }^{2, *}$ \\ Mohammad Esmaeil Akbari ${ }^{1} *$ \\ 'Cancer Research Centre, Shahid \\ Beheshti University of Medical Sciences, \\ Tehran, Iran; ${ }^{2}$ Department of Research \\ and Development, Sodour Ahrar Shargh \\ Company, Tehran, Iran; ${ }^{3}$ Department of \\ Hematology, Faculty of Medical Sciences, \\ Tarbiat Modares University, Tehran, Iran; \\ ${ }^{4}$ Department of Statistics, Faculty of \\ Sciences, University of Qom, Qom, Iran; \\ ${ }^{5}$ Stem Cell Technology Research Center, \\ Tehran, Iran
}

*These authors contributed equally to this work
Correspondence: Mohammad Hassan Nazaran

Department of Research and

Development, Sodour Ahrar Shargh

Company, Tehran, I4I594434I, Iran

$\mathrm{Tel}+982188992123$

Fax +98 2188992123

Email mnazaran@nanochelatingtechnology. com

Mohammad Esmaeil Akbari

Cancer Research Center, Shahid Beheshti

University of Medical Sciences, Tehran,

1989934148, Iran

Tel +98212 2724090

$\mathrm{Fax}+982122749213$

Email crc@sbmu.ac.ir
Background: Our previous findings showed that $\mathrm{BCc} 1$, a nanoparticle designed based on nanochelating technology, can be considered a new anti-cancer nanoparticle if confirmed by complementary studies.

Goal: In the present study, we investigated the effects of the BCc1 nanoparticle alone on some gene expressions influencing the apoptosis pathway, and also the effect of the mixture of BCc1 nanoparticle and doxorubicin on survival.

Method: Using an in vitro study, the effects of the BCc1 nanoparticle on Bax, Bcl2, p53, Caspase 7 and p21 gene expressions were assessed after a 24-h treatment using real-time PCR in MCF-7 and MEFs; in addition, using an in vivo study, 4T1 tumor-bearing female Balb/c mice were treated with different doses of the $\mathrm{BCc} 1$ nanoparticle and doxorubicin alone and together and then their mean and median survival was evaluated.

Result: The results showed that the $\mathrm{BCc} 1$ nanoparticle increased gene expressions of $\mathrm{RB}$, p53, Caspase7, p21, and Bax and decreased gene expressions of Bcl2 in MCF-7 significantly, but no change was observed in MEFs expressions. The findings revealed that the $\mathrm{BCc} 1$ nanoparticle, when used orally, had the highest mean and median survival time. A mixture of a high dose of the BCc1 nanoparticle $(1 \mathrm{mg} / \mathrm{kg})$ and a low dose of doxorubicin $(0.1 \mathrm{mg} / \mathrm{kg})$ showed synergistic effects on enhanced life span, while doxorubicin dose was prescribed approximately 50 times less than the murine applicable dose $(5 \mathrm{mg} / \mathrm{kg})$.

Conclusion: Our results demonstrated that the $\mathrm{BCc} 1$ nanoparticle not only has the potential to become a novel nanomedicine for cancer therapy, but it can also provide the basis of a new medicine for cancer management when mixed with a lower applicable dose of doxorubicin. Keywords: BCc1 nanoparticle, cancer, doxorubicin, nanochelating technology, murine 4T1 tumor model

\section{Introduction}

In the next 20 years, the number of new cancer cases is forecast to increase by almost $70 \%{ }^{1,2}$ To date chemotherapy has been considered a standard treatment for all kinds of cancers; however, the outcomes of this kind of treatment are not desirable enough, so in recent years, by shedding more light on molecular pathways, tumor biology, tumor-host interactions and tumor microenvironment, new combination therapies, ${ }^{3-5}$ including chemotherapy with targeted therapy, chemotherapy with immunotherapy and chemotherapy with gene therapy have been developed. ${ }^{6}$

Doxorubicin, an antineoplastic agent, has been widely used, either alone or in combination with other chemotherapy drugs, as a chemotherapeutic agent since the 
1960s. ${ }^{7,8}$ However, the clinical use of this drug is harmful due to its damaging effects on heart, ${ }^{9}$ hepatotoxicity, ${ }^{10}$ hematologic index, etc. ${ }^{11-13}$ Nowadays, researchers aim to find some compounds that are able to neutralize the toxic effect of doxorubicin, while maintaining the antitumor effect of the drug. ${ }^{14}$ To achieve this, doxorubicin is administered in a liposomal formulation, permitting patients to be treated with higher lifetime doses. Additionally, well-tolerated doxorubicin can be beneficial to a great extent combined with other regimens in order to enhance tolerability or allow the combination partners to be delivered at higher doses. ${ }^{15}$

Nanotechnology envisages a breakthrough in the domain of cancer therapy owing to its unique properties and functions. ${ }^{16}$ This technology is completely flexible as it permits scientists to engineer drug nanoparticles of dimensions $10-500 \mathrm{~nm}$, enabling them to pass through the leaky vasculature of the tumorigenic microenvironment with higher specificity and reduced cytotoxicity. ${ }^{17}$

Nanochelating technology, a new branch of nanotechnology, has recently proved its noticeable impact in various sciences by synthesizing unique nanostructures. ${ }^{18}$ In our previous report, MSc1 nanocomplex, synthesized by nanochelating technology, exhibited therapeutic effects in an animal model of multiple sclerosis. ${ }^{19}$ Also, in an experimental model of Parkinson disease, Maghsoudi et al revealed neuroprotective effects of three nanochelating-based nanocomplexes. ${ }^{20}$ According to our other experiments, GFc7 nanocomplex (an iron-containing copper chelator nanocomplex) improved cell proliferation in addition to maintaining and increasing pluripotency properties of Human Mesenchymal Stem Cells (HMSC). ${ }^{21}$

Using an in vitro study, we have already investigated the anticancer effects of the $\mathrm{BCcl}$ nanoparticle (45-47 nm), designed based on nanochelating technology by a self-assembly method, ${ }^{22}$ and the results demonstrated that although $\mathrm{BCc} 1$ nanoparticle cell toxicity was higher for cancer cells than normal ones, it did not affect the viability of healthy cells at a fixed concentration and could increase the percentage of early and late apoptosis in cancer cells as compared to control. Likewise, the G1 phase percentage increased from $59 \%$ to $70 \%$, while $\mathrm{S}$ and G2/M phases percentages decreased from $15 \%$ to $12 \%$ and $26 \%$ to $18 \%$, respectively. Additionally, the report of our in vivo study showed that the $\mathrm{BCc} 1$ nanoparticle led to an increase in survival and decrease in the growth of tumor size in breast cancer-bearing $\mathrm{Balb} / \mathrm{c}$ mice without anemia. $^{22}$
Nowadays, many tumor suppressor genes are found to be effective in cell cycle control. Tumor suppressor genes usually prevent or reduce the likelihood of malignant transformation. However, a tumor suppressor gene efficiency loss puts a cell at risk of neoplastic transformation. ${ }^{23}$

Previous studies have revealed the function of various tumor suppressor genes in cells. P53, nicknamed the "guardian of the genome," is proven to be vital to cell division control. ${ }^{24}$ It takes part in the cell cycle checkpoint pathway and apoptosis ${ }^{24}$ and also controls multiple genes, including p21, associated with G1 phase arrest. ${ }^{25}$ Similarly, it is also confirmed that cyclin-dependent kinase inhibitor p21 develops cell cycle arrest in response to various stimuli and prevents cellular proliferation independent of CDK2, needed for $\mathrm{S}$ phase progression. ${ }^{26}$ The retino blastoma (RB) functions to prevent excessive cell growth by controlling cell cycle progression until a cell is ready to divide; therefore, its dysfunctionality ${ }^{27}$ is the cause of some major cancers.

The balance between the pro-apoptotic gene Bax and anti-apoptotic gene B-cell lymphoma 2 (Bcl-2) is crucial in cell development, and abnormal expression of Bax and Bcl-2 sets off apoptosis through the mitochondrial pathway. ${ }^{28}$ Some other studies have proven the key role of Caspase7 in mediating apoptosis and association between Caspase family members and cancer risk. ${ }^{29}$

In the present study, we investigated cancer and normal cells treatment by the $\mathrm{BCc} 1$ nanoparticle so as to compare tumor suppressor gene expressions in both kinds of cells considering the fact that $\mathrm{BCc}$ 1nanoparticle can cause apoptosis, so we opted for some genes that affect the apoptosis pathway, such as RB, Bax, Bcl2, p53, Caspase7, and p21, described above.

Moreover, we intended to investigate the effect of oral dose of the $\mathrm{BCc} 1$ nanoparticle on survival in metastatic animal modeling and also the effect of a mixture of doxorubicin and $\mathrm{BCc} 1$ nanoparticle on survival when used through injection where doxorubicin was applied in a murine applicable dose $(5 \mathrm{mg} / \mathrm{kg})$ and a low dose $(0.1 \mathrm{mg} / \mathrm{kg})$ as well; that is, 50 times less than its murine applicable dose. ${ }^{30,31}$ Mice mammary carcinoma cells (4T1) were selected for animal modeling as this is a metastatic cell line that can attack liver, lung and brain tissues by rapid cell division. ${ }^{32}$

\section{Materials and methods}

\section{Chemicals}

The BCc1 nanoparticle was obtained from (Tehran, Iran). DMEM, FBS, PBS, penicillin G, streptomycin (100 mg/ 
$\mathrm{mL}$ ), and $0.25 \%$ trypsin-ethylene diamine tetraacetic acid were from Gibco-Life Technologies (Carlsbad, CA, USA). Doxorubicin $\mathrm{HCl}$ liposome was from Sobhan Oncology (Tehran, Iran).

\section{$\mathrm{BCcl}$ nanoparticle}

BCc1 nanoparticle ${ }^{22}$ with antineoplastic effect, which is a new product patented as "Nanochelating Technology" in the US Patent and Trademark Office (USPTO), ${ }^{18}$ was synthesized according to the protocol explained in the previous study.

\section{Cell culture conditions}

The 4T1 cell line, mouse embryonic fibroblasts (MEFs), and Michigan Cancer Foundation-7 (MCF7) cell line were prepared from the National Cell Bank of Pasteur Institute (Tehran, Iran) and were cultured in DMEM supplemented with $10 \%$ FBS, penicillin $\mathrm{G}$, and streptomycin.

MEFs and MCF-7 cells were cultured in a humidified incubator in an atmosphere of $95 \%$ air and $5 \% \mathrm{CO} 2$ at $37^{\circ} \mathrm{C}$ and seeded onto 6-well plates in triplicate wells, while the cells were maintained with a fresh medium containing BCc1 nanoparticle for $24 \mathrm{~h}$ and then $\mathrm{p} 53, \mathrm{p} 21, \mathrm{Bax}, \mathrm{Bcl} 2$, Caspase7, and RB gene expressions were investigated.

\section{Gene transcription evaluation}

Total RNA was extracted using trizol following the manufacturer's instructions. Synthesis of cDNA was performed with $\mathrm{M}-\mathrm{MuLV}$ reverse transcriptase and oligo primers. Gene quantification \& real time PCR quantification (qRTPCR) analysis was conducted using a standard SYBR Green PCR kit protocol on a Rotor Gene 6000 instrument. ${ }^{33,34}$ Data were normalized by glyceraldehyde3-phosphate dehydrogenase (GAPDH) as the endogenous control gene. The relative mRNA expression levels were measured according to the $\Delta \mathrm{CT}$ method.

\section{Cell viability assessment}

Staining solution, containing propidium iodide (PI) as a reverse indicator of cell viability, was added to the cells and incubated for $1 \mathrm{~min}$ in the dark. Following that, PI was assessed by flow cytometry analysis (FACS) to quantify the exact number of cell viability. ${ }^{21}$

\section{Animals and ethics approval}

Seven-to-eight-week-old inbred female Balb/c mice were purchased from Pasteur Institute, Tehran, Iran. All mice were maintained in large group houses where they were accustomed for 1 week before the test and kept at standard conditions during the study; $24 \pm 2^{\circ} \mathrm{C}$ temperature, $50 \pm 10 \%$ relative humidity, and $12 \mathrm{~h}$ light/12 h dark cycle.

This animal study was conducted according to the relevant national and international guidelines of Shahid Beheshti University of Medical Sciences for the care and use of laboratory animals. It has also received the ethics approval of Shahid Beheshti University of Medical Sciences, Tehran, Iran; Reg. No. IR.SBMU.REC.1396.2.

\section{Animal experiment and treatment groups}

Before 4T1 cell line was injected to mice, the percentage of cell viability was measured and then $6 \times 10^{5}$ of cells were suspended in $100 \mu \mathrm{L}$ of PBS and injected into the second mammary fat pad of female Balb/c mice. During the test, the mice were monitored once every three days after injection and then tumor tissues became noticeable after almost 10 days. Following that, the mice were randomly divided into 10 groups, with 8 in each. All groups were treated via IP injection except one which was treated orally.

The dates on which mice died and their other observable symptoms were investigated and recorded; the sick and moribund animals were excluded from the study. Subsequently, means and medians for survival time of the animals were calculated. ${ }^{35}$

Treatments were categorized according to Table 1 , where doxorubicin applicable dose $(5 \mathrm{mg} / \mathrm{kg})$ and low dose $(0.1 \mathrm{mg} /$

Table I Design of dosages and study groups

\begin{tabular}{|c|c|c|}
\hline Groups & Treatments & Dosage \\
\hline Group I & Control & Distilled water \\
\hline Group 2 & BCcl nanoparticle low dose & $0.1 \mathrm{mg} / \mathrm{kg} /$ once a day \\
\hline Group 3 & $\mathrm{BCcl}$ nanoparticle high dose & I mg/kg/once a day \\
\hline Group 4 & Doxorubicin low dose & $0.1 \mathrm{mg} / \mathrm{kg} /$ once a day \\
\hline Group 5 & Doxorubicin applicable dose & $5 \mathrm{mg} / \mathrm{kg} /$ once a week \\
\hline Group 6 & $\begin{array}{l}\text { Mixture of } \mathrm{BCcl} \text { nanoparticle } \\
\text { (low dose) and doxorubicin } \\
\text { (low dose) }\end{array}$ & $\begin{array}{l}0.1 \mathrm{mg} / \mathrm{kg} / \text { once a day } \\
\text { and } 0.1 \mathrm{mg} / \mathrm{kg} / \text { once } \\
\text { a day }\end{array}$ \\
\hline Group 7 & $\begin{array}{l}\text { Mixture of } \mathrm{BCcl} \text { nanoparticle } \\
\text { (high dose) and doxorubicin } \\
\text { (applicable dose) }\end{array}$ & $\begin{array}{l}\mathrm{I} \mathrm{mg} / \mathrm{kg} / \text { once a day } \\
\text { and } 5 \mathrm{mg} / \mathrm{kg} / \text { once } \\
\text { a week }\end{array}$ \\
\hline Group 8 & $\begin{array}{l}\text { Mixture of } \mathrm{BCcl} \text { nanoparticle } \\
\text { (low dose) and doxorubicin } \\
\text { (applicable dose) }\end{array}$ & $\begin{array}{l}01 \mathrm{mg} / \mathrm{kg} / \text { once a day } \\
\text { and } 5 \mathrm{mg} / \mathrm{kg} / \text { once } \\
\text { a week }\end{array}$ \\
\hline Group 9 & $\begin{array}{l}\text { Mixture of } \mathrm{BCcl} \text { nanoparticle } \\
\text { (high dose) and doxorubicin } \\
\text { (low dose) }\end{array}$ & $\begin{array}{l}\text { I } \mathrm{mg} / \mathrm{kg} / \text { once a day } \\
\text { and } 0.1 \mathrm{mg} / \mathrm{kg} / \text { once } \\
\text { a day }\end{array}$ \\
\hline Group 10 & BCcl nanoparticle used orally & $10 \mathrm{mg} / \mathrm{kg} /$ once a day \\
\hline
\end{tabular}


$\mathrm{kg})$, and BCc1 nanoparticle high dose $(1 \mathrm{mg} / \mathrm{kg})$ and low dose $(0.1 \mathrm{mg} / \mathrm{kg})$ were prescribed for the present study.

\section{Statistical analysis}

Summary statistics of the data were reported as mean \pm standard error from at least 3 separate experiments conducted in triplicate, and means and medians for survival time were presented for all groups. In each group, the standard error and $95 \%$ confidence interval were reported for each of these indices.

Survival table for tracking dead time was obtained, yet not reported here. To compare the survival time between these groups, the well-known log-rank test was used as well as the Breslow and Tarone-Ware tests. For pairwise comparison (to know which 2 groups were different), the Wilcoxon test was employed, where the significance level was considered 0/05.

Survival analysis was conducted using life tables and the Kaplan-Meier method and statistical data analysis was computed using the SPSS Statistics version 25 software (IBM, Armonk, NY, USA).

\section{Results}

\section{Tumor suppressor gene expressions}

As shown in Figure 1, the gene expressions of Bax in MEFs and MCF-7 were $0.84 \pm 0.012$ and $1.77 \pm 0.015$, respectively, and gene expressions of Bcl2 in MEFs and MCF-7 were $0.75 \pm 0.1$ and $0.91 \pm 0.1$. Therefore, the BCc1 nanoparticle significantly increased ratio of $\mathrm{Bax} / \mathrm{Bcl}-2$ in MCF-7 in comparison with MEFs.

As shown in Figure 2, the gene expressions of p21 in MEFs and MCF-7 were $0.72 \pm 0.05$ and $2.03 \pm 0.1$, respectively, and the gene expressions of p53 in MEFs and MCF7 were $0.63 \pm 0.08$ and $1.15 \pm 0.1$. Moreover, the gene expressions of Caspase 7 in MEFs and MCF-7 were 0.56 \pm 0.05 and $1.76 \pm 0$., respectively, and the gene expressions of RB in MEFs and MCF-7 were $0.57 \pm 0.06$ and 1.61 \pm 0.17 . Thus, these results show that tumor suppressor gene expressions ( 2 21, p53, Caspase7, and RB) significantly increased after $\mathrm{BCc} 1$ nanoparticle treatment in MCF-7 cells as compared to MEF cells.

\section{Cell viability}

PI cannot enter viable cells; however, it can permeate cell membranes of dying or dead cells. In this study, PI was utilized to assay cell viability by flow cytometry to quantify the exact percentage of viable cells compared to initial cultured cells as control. The percentage of cell viability for $4 \mathrm{~T} 1$ cell line before injecting the Balb/c mice was equal to $98 \pm 1 \%$ (Figure 3 ).

\section{Survival analysis in defined groups \\ - Median survival time}

In Table 2, the median survival time in each group is given. According to this table, the median survival time

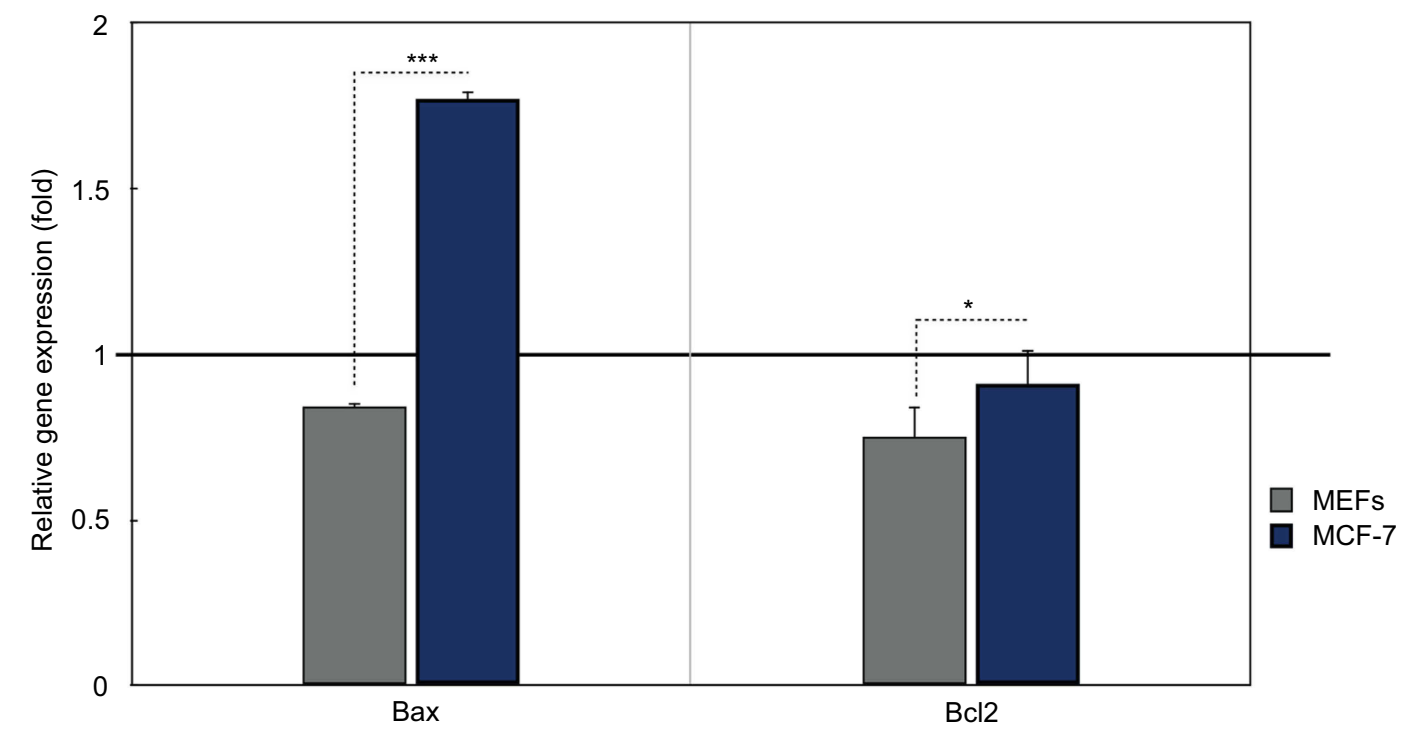

Figure I Effects of BCcInanoparticle on the relative expression level of Bax and Bcl2 genes in MCF-7 compared with MEF cells. The black horizontal line shows the onefold enrichment cutoff criteria; data are expressed as mean $\pm \mathrm{SD}$; asterisks show datasets that are significant at different levels: $* p<0.05, * * p<0.0 \mathrm{I}, * * * p<0.00 \mathrm{I}$.

Abbreviations: MEF, mouse embryonic fibroblast; MCF7, Michigan Cancer Foundation-7. 


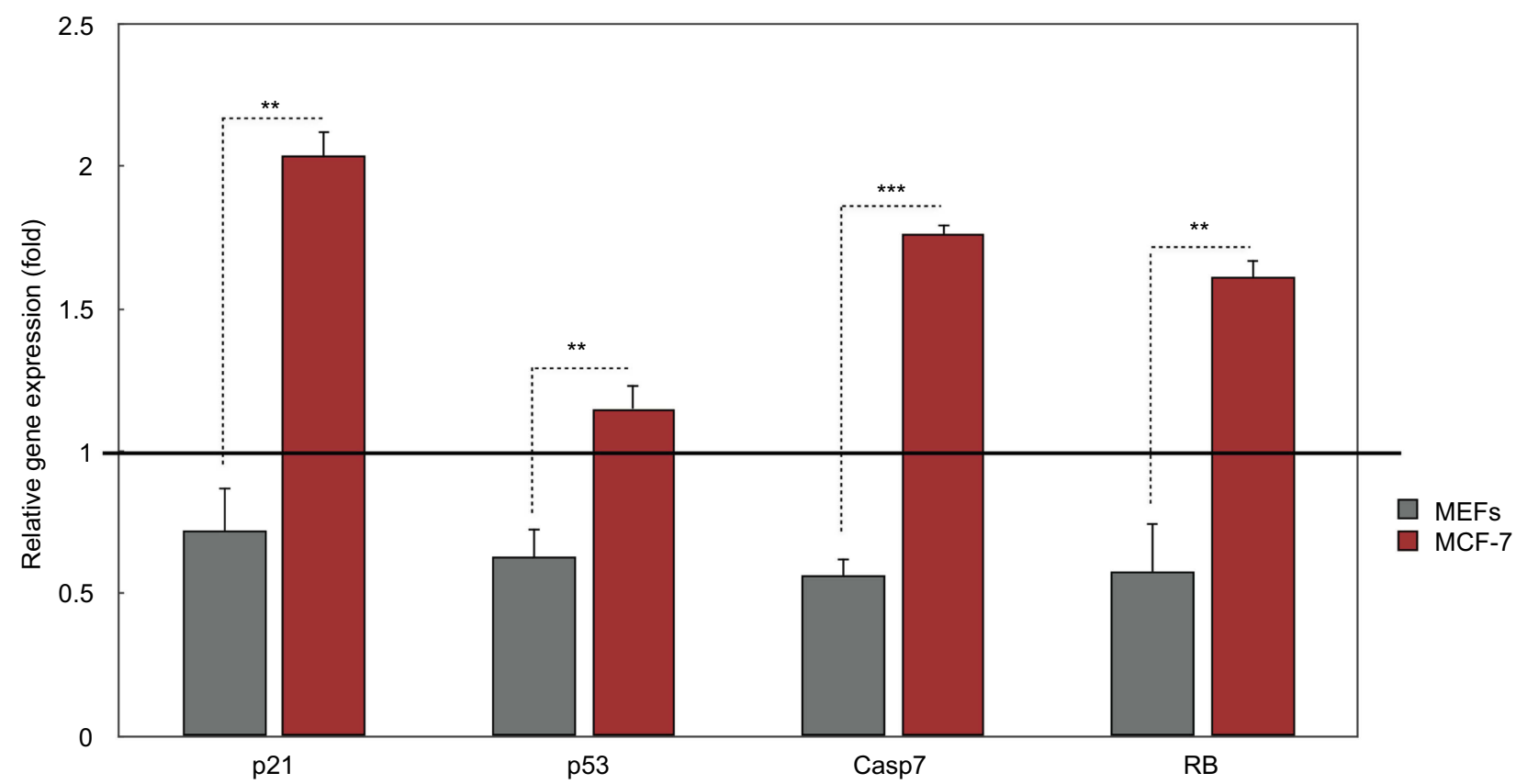

Figure 2 Effects of the $\mathrm{BCcl}$ nanoparticle on the relative expression level of Caspase7, p2I, p53, and RB genes in MCF-7 compared with MEF cells. The black horizontal line shows the onefold enrichment cutoff criteria; data are expressed as mean $\pm \mathrm{SD}$; asterisks show datasets that are significant at different levels: $* p<0.05$, $* * p<0.0 \mathrm{I}, * * * p<0.00 \mathrm{I}$. Abbreviations: MEF, mouse embryonic fibroblast; MCF7, Michigan Cancer Foundation-7; RB, Retino Blastoma.

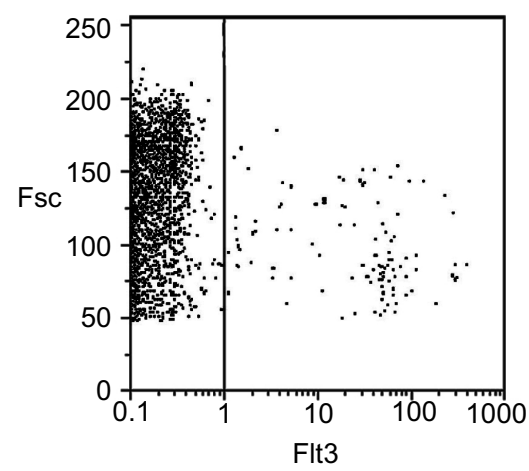

Figure 3 Viability assay of 4 TI cells by FACS instrument. Data are shown with a dot plot diagram.

Abbreviation: FACS, flow cytometry analysis.

in each group was as follows: control group: 19 days ( $95 \%$ CI: 11.30-26.69); $\mathrm{BCc} 1$ nanoparticle group (BCc1 used orally): 38 days (95\% CI: 33.1-42.8); BCc1 nanoparticle low dose group: 21 days (95\% CI: 18.6-23.4); $\mathrm{BCc} 1$ nanoparticle high dose group: 14 days $(95 \%$ CI: 4.3-23.6); doxorubicin low dose group: 14 days (95\% CI: 1.16-26.83); and doxorubicin applicable dose group: 23 days (95\% CI: 15.30-30.69). Also, the median survival time in each mixture group was as follows: $\mathrm{BCc1}$ nanoparticle low + doxorubicin low dose group: 29 days (95\% CI: 0-75); BCc1 nanoparticle high + doxorubicin applicable dose group: 9 days (95\% CI: 4.1-13.8); $\mathrm{BCc} 1$ nanoparticle low + doxorubicin applicable dose group: 12 days (95\% CI: 9.43-14.56); and BCc1 nanoparticle high + doxorubicin low dose group: 34 days $(95 \% \mathrm{CI}$ : 23.7-44.2).

In this table, the $p$-value for pairwise comparisons with respect to the control group is provided. Accordingly, the groups $(\mathrm{BCc} 1$ nanoparticle high + doxorubicin low and $\mathrm{BCc} 1$ nanoparticle, used orally) had different survival distributions with respect to the control group.

Thus, the results showed that in the groups which used $\mathrm{BCc} 1$ nanoparticle orally and the mixture of $\mathrm{BCc} 1$ nanoparticle high + doxorubicin low dose, the median survival times were 19 and 15 days significantly higher than the control group, respectively. The values of Wilcoxon statistics for these 2 comparisons were 4/592 and 4/198 with $p$-value equal to $0 / 032$ and $0 / 40$, respectively.

- Mean survival time

The mean survival times in each group are given in Table 3. According to this table, the mean survival time in each group was as follows: control group: 19.5 days (95\% CI: 12.3-26.84); BCc1 nanoparticle group (BCc1 used orally): 35.33 days (95\% CI: 27-43.65); BCc1 nanoparticle low dose group: 20.33 days (95\% CI: 14.16-26.50); BCc1 nanoparticle high dose group: 
Table 2 Median survival time

\begin{tabular}{|c|c|c|c|c|c|c|}
\hline Number & Groups & Estimate & $\begin{array}{l}\text { Standard } \\
\text { error }\end{array}$ & $\begin{array}{l}\text { Lower } \\
\text { bound } \\
\text { (95\% } \\
\text { CI) }\end{array}$ & $\begin{array}{l}\text { Upper } \\
\text { bound } \\
(95 \% \mathrm{CI})\end{array}$ & Significance \\
\hline 1 & Control & 19 & 3.928 & 11.301 & 26.699 & \\
\hline 2 & $\mathrm{BCcl}$ nanoparticle low dose & 21 & 1.225 & 18.600 & 23.400 & 0.721 \\
\hline 3 & BCcl nanoparticle high dose & 14 & 4.899 & 4.398 & 23.602 & 0.317 \\
\hline 4 & Doxorubicin low dose & 14 & 6.547 & 1.169 & 26.831 & 0.701 \\
\hline 5 & Doxorubicin applicable dose & 23 & 3.928 & $|5.30|$ & 30.699 & 0.609 \\
\hline 6 & $\begin{array}{l}\text { Mixture of BCcl nanoparticle (low dose) and doxoru- } \\
\text { bicin (low dose) }\end{array}$ & 29 & 23.568 & 0.000 & 75.192 & 0.749 \\
\hline 7 & $\begin{array}{l}\text { Mixture of BCcl nanoparticle (high dose) and doxoru- } \\
\text { bicin (applicable dose) }\end{array}$ & 9 & 2.449 & 4.199 & $13.80 \mid$ & 0.431 \\
\hline 8 & $\begin{array}{l}\text { Mixture of BCcl nanoparticle (low dose) and doxoru- } \\
\text { bicin (applicable dose) }\end{array}$ & 12 & 1.309 & 9.434 & 14.566 & 0.201 \\
\hline 9 & $\begin{array}{l}\text { Mixture of } \mathrm{BCcl} \text { nanoparticle (high dose) and doxoru- } \\
\text { bicin (low dose) }\end{array}$ & 34 & 5.237 & 23.735 & 44.265 & $0.040 *$ \\
\hline 10 & $\mathrm{BCcl}$ nanoparticle orally used & 38 & 2.449 & 33.199 & 42.801 & $0.032 *$ \\
\hline
\end{tabular}

Note: *According to this table the groups 9 and 10 have different survival distributions with respect to the control group.

Table 3 Mean survival time

\begin{tabular}{|c|c|c|c|c|}
\hline Groups & Estimate* & $\begin{array}{l}\text { Standard } \\
\text { error }\end{array}$ & $\begin{array}{l}\text { Lower } \\
\text { bound } \\
\text { (95\% } \\
\text { CI) }\end{array}$ & $\begin{array}{l}\text { Upper } \\
\text { bound } \\
(95 \% \mathrm{CI})\end{array}$ \\
\hline Control & 19.571 & 3.709 & 12.302 & 26.841 \\
\hline $\mathrm{BCcl}$ nanoparticle low dose & 20.333 & 3.148 & 14.163 & 26.504 \\
\hline $\mathrm{BCcl}$ nanoparticle high dose & 15.167 & 4.086 & 7.158 & 23.175 \\
\hline Doxorubicin low dose & 20.143 & 5.599 & 9.168 & 31.118 \\
\hline Doxorubicin applicable dose & 20.143 & 2.530 & 15.184 & 25.102 \\
\hline Mixture of $\mathrm{BCcl}$ nanoparticle (low dose) and doxorubicin (low dose) & 21.429 & 4.582 & 12.448 & 30.409 \\
\hline $\begin{array}{l}\text { Mixture of } \mathrm{BCcl} \text { nanoparticle (high dose) and doxorubicin (applicable } \\
\text { dose) }\end{array}$ & 16.000 & 4.099 & 7.966 & 24.034 \\
\hline $\begin{array}{l}\text { Mixture of } \mathrm{BCcl} \text { nanoparticle (low dose) and doxorubicin (applicable } \\
\text { dose) }\end{array}$ & 12.857 & 1.870 & 9.192 & 16.522 \\
\hline Mixture of $\mathrm{BCcl}$ nanoparticle (high dose) and doxorubicin (low dose) & 32.000 & 3.359 & 25.416 & 38.584 \\
\hline $\mathrm{BCcl}$ nanoparticle used orally & 35.333 & 4.248 & 27.007 & 43.659 \\
\hline
\end{tabular}

Note: *Estimation is limited to the largest survival time if it is censored.

15.16 days (95\% CI: 7.15-23.17); doxorubicin low dose group: 20.14 days $(95 \%$ CI: $9.16-31.11)$; and doxorubicin applicable dose group: 20.14 days $(95 \% \mathrm{CI}$ : 15.18-25.10). Also, the mean for survival time in each mixture group was as follows: $\mathrm{BCc} 1$ nanoparticle low + doxorubicin low dose group: 21.42 days (95\% CI: 12.44-30.40); BCc1 nanoparticle high + doxorubicin applicable dose group: 16 days (95\% CI: 7.96-24.03); BCc1 nanoparticle low + doxorubicin applicable dose group: 12.85 days (95\% CI: 9.19-16.52); and BCc1 nanoparticle high + doxorubicin low dose group: 32 days (95\% CI: $25.41-38.58)$.

Thus, the results showed that in the groups which used $\mathrm{BCc} 1$ nanoparticle orally, and the mixture of $\mathrm{BCc} 1$ nanoparticle high + doxorubicin low dose, the mean survival times were higher than in the control group.

The plots of hazard and survival functions of all groups are given in Figures 4 and 5, respectively. 
According to these figures, the cases in the groups which used $\mathrm{BCc} 1$ nanoparticle orally and the mixture of BCc1 nanoparticle high + doxorubicin low dose group had higher survival and lower hazard in respect to the cases of other groups.

\section{Discussion}

Cancer is still known as one of the most challenging global health-care issues around the world and is defined as the uncontrolled growth of cells. Accelerating cell division rates

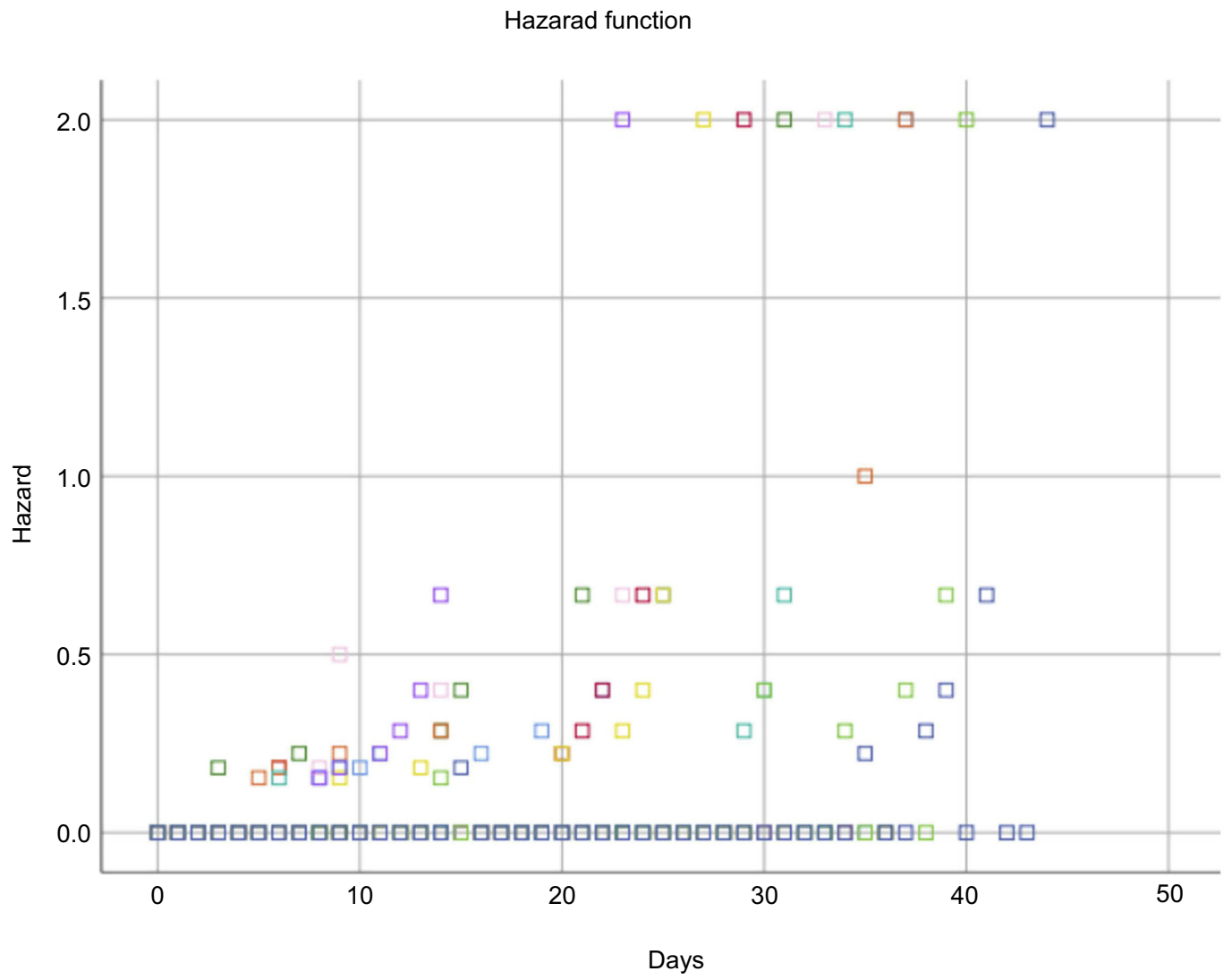

$\square$ Control

BCc1nanoparticle low dose

BCc1nanoparticle high dose

Doxorubicin low dose

Doxorubicin applicable dose

Mixture of BCc1nanoparticle (low dose) and doxorubicin (low dose)

Mixture of BCc1nanoparticle (high dose) and doxorubicin (applicable dose)

Mixture of BCc1nanoparticle (low dose) and doxorubicin (applicable dose)

Mixture of BCc1nanoparticle (high dose) and doxorubicin (low dose)

$\square$ BCc1 1nanoparticle orally used

Figure 4 The hazard function in the groups which used $\mathrm{BCcl}$ nanoparticle orally, and the mixture of BCcl nanoparticle low dose and doxorubicin applicable dose showed a lower hazard than other groups. 


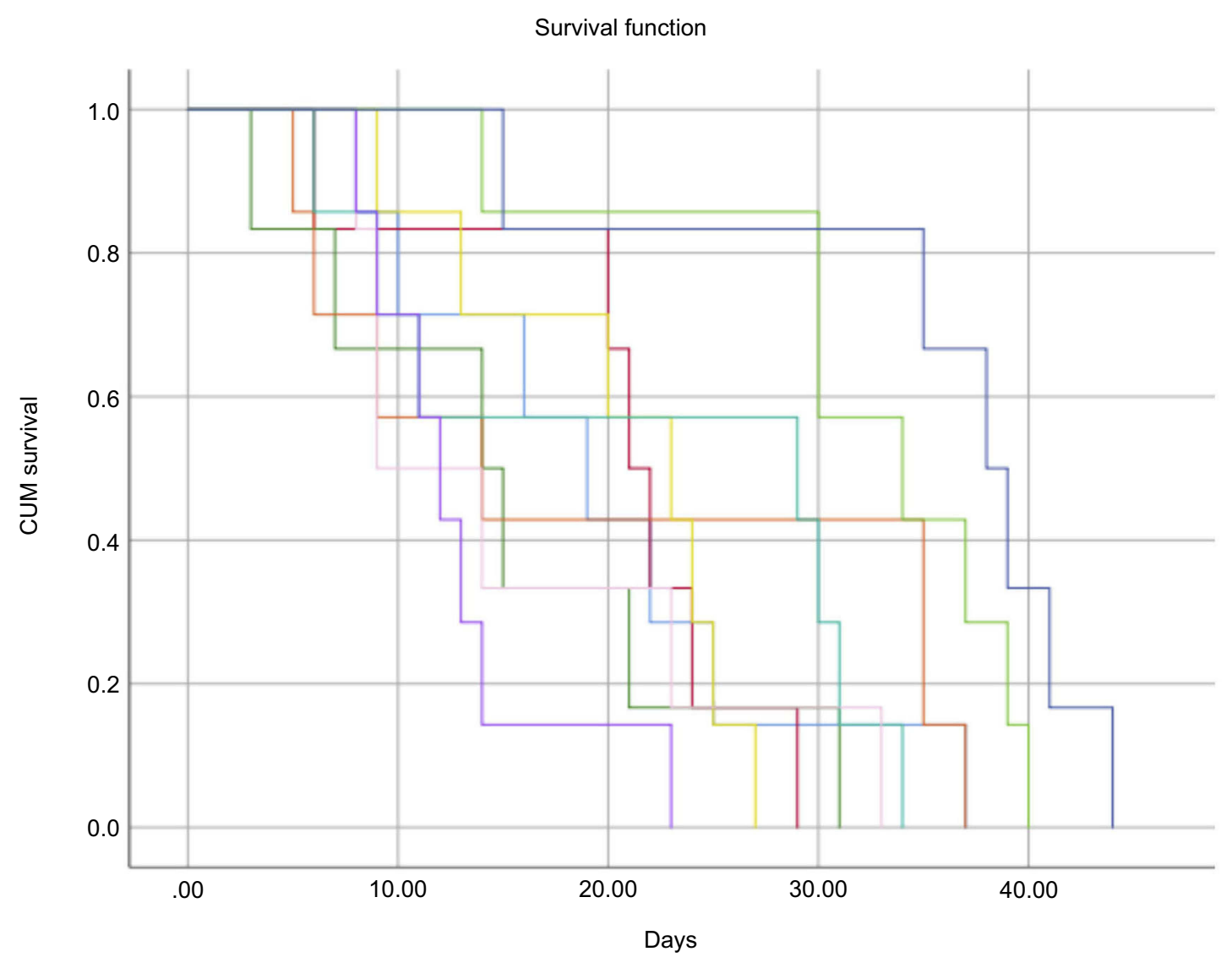

$\square$ Control

BCc1nanoparticle low dose

BCc1nanoparticle high dose

Doxorubicin low dose

Doxorubicin applicable dose

Mixture of BCc1nanoparticle (low dose) and doxorubicin (low dose)

Mixture of BCc1nanoparticle (high dose) and doxorubicin (applicable dose)

Mixture of BCc1nanoparticle (low dose) and doxorubicin (applicable dose)

Mixture of BCc1nanoparticle (high dose) and doxorubicin (low dose)

BCc1nanoparticle orally used

Figure 5 Kaplan - Meier diagram of survival diagram in the groups which used BCcl nanoparticle orally, and the mixture of BCclnanoparticle low dose and doxorubicin applicable dose showed higher survival than other groups.

Abbreviation: Cum, Cumulative

or inhibiting normal controls on the system can be caused by mutations in cancer genes, such as cell cycle arrest or programmed cell death. ${ }^{36}$

Doxorubicin is one of the most useful chemotherapy drugs in cancer therapy and Doxil ${ }^{\circledR}$ (liposomal doxorubicin) is the first generation of nanomedicine approved clinically in the last two decades, yet the most common cytotoxic drug. It has a metabolic activity increasing free radical generation and oxidative stress induction, so it causes an imbalance between reactive oxygen species (ROS) and antioxidant enzymes, resulting in liver cell damage and cardiomyopathy in patients. ${ }^{10}$ 
Omaima reported that a combination of selenium nanoparticles and doxorubicin is more effective on hepatocellular carcinoma than doxorubicin, when used alone. ${ }^{10} \mathrm{Kim}$ found out that the consumption of erythropoietin is useful in the reduction of cardiomyopathy in patients treated with doxorubicin. ${ }^{37}$ Lamkanfi reported that Free DOX did not increase the mice survival significantly, while DOX-Lip increased the life-spans $35 \%{ }^{38}$

Nanochelating technology, patented ${ }^{21}$ as a new approach, has already proven its dramatic impact in the treatment of various diseases by different nanoparticles possessing effective properties. Additionally, it introduces a new generation of nanoparticles with therapeutic properties that do not need any carriers, unlike other nanoparticles loaded with drugs. ${ }^{22}$

In vitro and in vivo studies showed that the $\mathrm{BCc} 1$ nanoparticle with iron chelating property has high potentials of inducing therapeutic behavior. Our previous study with FACS method proved that $\mathrm{BCc} 1$ nanostructure can decrease cell viability in cancer cells using apoptosis and arrest G1/S phase in treated cells. For the same reason, we investigated some gene expressions affecting apoptosis mechanism both in cancer and normal cells. It is proven that an increase in p53 decreases the expressions of the apoptosis-suppressing gene $\mathrm{Bcl}-2$, while simultaneously stimulating an increase in Bax gene expression. P53 anticancer function is through apoptosis, genomic stability, and inhibition of angiogenesis, and it can also arrest growth by holding the cell cycle and activate DNA repair proteins when DNA sustains damage.

In this study, $\mathrm{BCc} 1$ nanoparticle significantly increased the ratio of $\mathrm{Bax} / \mathrm{Bcl}-2$ in cancer cells compared to normal cells. Also, we observed that it increased p53 in cancer cells but did not cause any changes in normal cells, so the results signified the presence of apoptosis pathway in cancer cells.

P21 is one of the main engines driving cellular transformation whose malfunction can result in losing proper control of the mammalian cell cycle. The different physiological responses caused by 21 are intertwined. For example, cell cycle arrest induced by $\mathrm{p} 21$ enhances DNA repair by providing the damaged DNA with enough time to get fixed before being sent to daughter cells, so this is a key path by which p21 exercises its anti-apoptotic activities. ${ }^{26}$ Some studies have demonstrated that RB performs in a pathway which is often inactivated in most human cancers. ${ }^{25}$ Successive activation of caspases has a key role in the execution-phase of cell apoptosis. ${ }^{39}$ This fact made us investigate Caspase7, which is a caspase (cysteine aspartate protease) protein family member. The analyses of tumor suppressor genes revealed that $\mathrm{BCc} 1$ nanoparticle treatment increased $\mathrm{p} 21$, $\mathrm{RB}$, and Caspase7 gene expressions in cancer cells but did not increase healthy cells much.

The results of molecular analyses phase in the present study and flow cytometry in the previous one confirm each other, so these results subsequently prove the hypothesis that the BCc1 nanoparticle can intelligently activate the apoptosis cycle in cancer cells and then stop them, yet the apoptosis cycle does not get activated in healthy cells when used at a favorable dose.

Our previous animal study performed on breast cancerbearing Balb/c mice showed that treating mice with the $\mathrm{BCc} 1$ nanoparticle, when used intraperitoneally, reduces tumor cells growth and increases survival compared to a control group, but in the present study it was attempted to investigate its effect when used orally, the results of which showed that median and mean survival times in the $\mathrm{BCc} 1$ nanoparticle group increased compared to other groups.

The comparison of the mixture of $\mathrm{BCc} 1$ nanoparticle and doxorubicin in four combinations [BCc1 nanoparticle (high dose) and doxorubicin (applicable dose), BCc1 nanoparticle (low dose) and doxorubicin (low dose), BCc1 nanoparticle (applicable dose) and doxorubicin (low dose), and $\mathrm{BCc} 1$ nanoparticle (low dose) and doxorubicin (applicable dose)] revealed that the mixture of $\mathrm{BCc} 1$ nanoparticle in high dose and doxorubicin in low dose led to a higher median and mean survival times. Therefore, it can be claimed that there is a synergism effect between $\mathrm{BCc} 1$ nanoparticle and doxorubicin.

Currently, scientists apply various technologies to reduce the toxicity of chemotherapy agents and increase their efficacy, especially by nanotechnology that improves the bioavailability of medicines and "thus enhances efficacy without any need for higher doses". ${ }^{40,41}$ Therefore, nanotechnology can result in a difference in patients and the clinical outcomes, as the maximum tolerated dose of the active agent can be improved by preventing tolerability problems. ${ }^{14}$

According to the results of the present study, survival could be increased by the $\mathrm{BCcl}$ nanoparticle mixture, while the doxorubicin dose was one-fiftieth of its murine applicable dose. So this is a novel approach having the potential to be evaluated and optimized in further studies.

\section{Conclusion}

Although doxorubicin dose was reduced by 50 times, survival increased by $48 \%$ compared to control, so it can be claimed that this favorable result was due to the mixture 
of doxorubicin with the BCc1 nanoparticle, and we can achieve a new chemotherapy regime by reducing the doxorubicin dose. Moreover, the BCc1 nanoparticle can be regarded as an independent medicine for the treatment of cancer by complementary studies in the future.

\section{Acknowledgments}

The authors appreciate the support of Shahid Beheshti University of Medical Sciences, Cancer Research Centre at Shahid Beheshti University of Medical Sciences and Department of Research and Development at Sodour Ahrar Shargh Company, Tehran, Iran. This paper is part of Maryam Hafizi's PhD thesis, named "Evaluation of nanochelating based nanomedicine, BCc1, using cellular and animal model of cancer and then safety and efficacy study in metastatic and non-metastatic Gastric Cancer patients".

\section{Disclosure}

Mr Mohammad Hassan Nazaran reports a patent US8288587B2 with royalties paid. The authors report no other conflicts of interest in this work.

\section{References}

1. Siegel RL, Miller KD, Fedewa SA, et al. Colorectal cancer statistics, 2017. CA Cancer J Clin. 2017;67(3):177-193. doi:10.3322/caac.21395

2. Gupta SK, Garg A, Bar C, et al. Quaking inhibits doxorubicin-mediated cardiotoxicity through regulation of cardiac circular RNA expression. Circ Res. 2018;122(2):246-254. doi:10.1161/CIRCRESAHA.117.3 11335

3. Liu Y, Jia Q, Guo Q, Wei W, Zhou J. Simultaneously activating highly selective ratiometric MRI and synergistic therapy in response to intratumoral oxidability and acidity. Biomaterials. 2018;180:104-116. doi:10.1016/j.biomaterials.2018.07.025

4. Zhu X, Li J, Qiu X, Liu Y, Feng W, Li F. Upconversion nanocomposite for programming combination cancer therapy by precise control of microscopic temperature. Nat Commun. 2018;9(1):2176. doi:10.1038/ s41467-018-04571-4

5. Yuxin Liu QG, Zhu X, Feng W, et al. Optimization of prussian blue coated NaDyF4: $\mathrm{x} \%$ LuNanocomposites for multifunctional imagingguided photothermal therapy. Adv Funct. 2016;26,:5120. doi:10.1002/ adfm. 201601478

6. Zhang RX, Wong HL, Xue HY, Eoh JY, Wu XY. Nanomedicine of synergistic drug combinations for cancer therapy - strategies and perspectives. J Control Release. 2016;240:489-503. doi:10.1016/j. jconrel.2016.06.012

7. Johnson-Arbor K, Dubey R. Doxorubicin. In: StatPearls. Treasure Island, FL; 2018. Available from https://www.ncbi.nlm.nih.gov/ books/NBK459232/.Last accessed 31 May 2019.

8. Xu YC, Liu X, Li M, et al. A novel mechanism of doxorubicin resistance and tumorigenesis mediated by MicroRNA-501-5psuppressed BLID. Mol Ther Nucleic Acids. 2018;12:578-590. doi:10.1016/j.omtn.2018.06.011

9. Iwamoto T. Clinical application of drug delivery systems in cancer chemotherapy: review of the efficacy and side effects of approved drugs. Biol Pharm Bull. 2013;36(5):715-718. doi:10.1248/bpb.b1201102
10. Abd El-Moneim OM, Abd El-Rahim AH, Hafiz NA. Evaluation of selenium nanoparticles and doxorubicin effect against hepatocellular carcinoma rat model cytogenetic toxicity and DNA damage. Toxicol Rep. 2018;5:771-776. doi:10.1016/j.toxrep.2018.07.003

11. Li S, Yuan S, Zhao Q, Wang B, Wang X, Li K. Quercetin enhances chemotherapeutic effect of doxorubicin against human breast cancer cells while reducing toxic side effects of it. Biomed Pharmacother. 2018;100:441-447. doi:10.1016/j.biopha.2018.02.055

12. Available from: https://www.rxlist.com/consumer_doxorubicin_adria mycin/drugs-condition.htm.

13. Grigorian A, O`Brien CB. Hepatotoxicity secondary to chemotherapy. J Clin Transl Hepatol. 2014;2(2):95-102. doi:10.1 4218/JCTH.2014.00011

14. Balsari A, Menard S, Colnaghi MI, Ghione M. Anti-drug monoclonal antibodies antagonize toxic effect more than anti-tumor activity of doxorubicin. Int J Cancer. 1991;47(6):889-892.

15. Hare JI, Lammers T, Ashford MB, Puri S, Storm G, Barry ST. Challenges and strategies in anti-cancer nanomedicine development: an industry perspective. Adv Drug Deliv Rev. 2017;108:25-38. doi:10.1016/j.addr.2016.04.025

16. Zhao CY, Cheng R, Yang Z, Tian ZM. Nanotechnology for cancer therapy based on chemotherapy. Molecules. 2018;23:4.

17. Sharma M, Pandey C, Sharma N, Kamal MA, Sayeed U, Akhtar S. Cancer nanotechnology - an excursion on drug delivery systems. Anticancer Agents Med Chem. 2018;18(15):2078-2092.

18. Nazaran MH. Chelate compounds. Google Patents US8288587B2. 2012.

19. Fakharzadeh S, Sahraian MA, Hafizi M, et al. The therapeutic effects of MSc1 nanocomplex, synthesized by nanochelating technology, on experimental autoimmune encephalomyelitic C57/BL6 mice. Int J Nanomedicine. 2014;9:3841-3853. doi:10.2147/IJN.S64630

20. Maghsoudi A, Fakharzadeh S, Hafizi M, et al. Neuroprotective effects of three different sizes nanochelating based nano complexes in $\mathrm{MPP}(+)$ induced neurotoxicity. Apoptosis. 2015;20(3):298-309. doi:10.1007/s10495-014-1069-x

21. Hafizi M, Hajarizadeh A, Atashi A, et al. Nanochelating based nanocomplex, GFc7, improves quality and quantity of human mesenchymal stem cells during in vitro expansion. Stem Cell Res Ther. 2015;6:226. doi:10.1186/s13287-015-0216-9

22. Kalanaky S, Hafizi M, Fakharzadeh S, et al. BCc1, the novel antineoplastic nanocomplex, showed potent anticancer effects in vitro and in vivo. Drug Des Devel Ther. 2016;10:59-70. doi:10.2147/ DDDT.S89694

23. Sherr CJ. Principles of tumor suppression. Cell. 2004;116 (2):235-246.

24. Efeyan A, Serrano M. p53: guardian of the genome and policeman of the oncogenes. Cell Cycle. 2007;6(9):1006-1010. doi:10.4161/cc.6.9.4211

25. Waldman T, Kinzler KW, Vogelstein B. p21 is necessary for the p53-mediated G1 arrest in human cancer cells. Cancer Res. 1995;55(22):5187-5190.

26. Romanov VS, Rudolph KL P21 shapes cancer evolution. Nat Cell Biol. 2016;18(7):722-724. doi:10.1038/ncb3382

27. Knudson AG Jr. Mutation and cancer: statistical study of retinoblastoma. Proc Natl Acad Sci U S A. 1971;68(4):820-823. doi:10.1073/pnas.68.4.820

28. Mischiati C, Puviani AC, Brogli M, et al. Modulation of pro-apoptotic (Bax) and anti-apoptotic (Bcl-2) gene expression in isolated porcine hepatocytes perfused within a radial-flow bioreactor after low-temperature storing. Int J Artif Organs. 2003;26(2):139-148.

29. Fan TJ, Han LH, Cong RS, Liang J. Caspase family proteases and apoptosis. Acta Biochim Biophys Sin (Shanghai). 2005;37(11):719-727.

30. Eralp Y, Wang X, Wang JP, Maughan MF, Polo JM, Lachman LB. Doxorubicin and paclitaxel enhance the antitumor efficacy of vaccines directed against HER 2/neu in a murine mammary carcinoma model. Breast Cancer Res. 2004;6(4):R275-83. doi:10.1186/ bcr787 
31. Bandyopadhyay A, Wang L, Agyin J, et al. Doxorubicin in combination with a small TGFbeta inhibitor: a potential novel therapy for metastatic breast cancer in mouse models. PLoS One. 2010;5(4): e10365. doi:10.1371/journal.pone.0010365

32. Baliga MS, Meleth S, Katiyar SK. Growth inhibitory and antimetastatic effect of green tea polyphenols on metastasis-specific mouse mammary carcinoma $4 \mathrm{~T} 1$ cells in vitro and in vivo systems. Clin Cancer Res. 2005;11(5):1918-1927. doi:10.1158/1078-0432.CCR04-1976

33. Gharibi B, Hughes FJ. Effects of medium supplements on proliferation, differentiation potential, and in vitro expansion of mesenchymal stem cells. Stem Cells Transl Med. 2012;1(11):771-782. doi:10.5966/ sctm.2010-0031

34. Hafizi M, Bakhshandeh B, Soleimani M, Atashi A. Exploring the enkephalinergic differentiation potential in adult stem cells for cell therapy and drug screening implications. In Vitro Cell Dev Biol Anim. 2012;48(9):562-569. doi:10.1007/s11626-012-9546-4

35. Hejazi E, Nasrollahzadeh J, Fatemi R, et al. Effects of combined soy isoflavone extract and docetaxel treatment on murine 4T1 breast tumor model. Avicenna J Med Biotechnol. 2015;7(1):16-21.
36. Bosch FX, Ribes J, Diaz M, Cleries R. Primary liver cancer: worldwide incidence and trends. Gastroenterology. 2004;127(5 Suppl 1):S5-S16.

37. Kim KH, Oudit GY, Backx PH. Erythropoietin protects against doxorubicin-induced cardiomyopathy via a phosphatidylinositol 3-kinase-dependent pathway. J Pharmacol Exp Ther. 2008;324 (1):160-169. doi:10.1124/jpet.107.125773

38. Mayhew EG, Goldrosen MH, Vaage J, Rustum YM. Effects of liposome-entrapped doxorubicin on liver metastases of mouse colon carcinomas 26 and 38. J Natl Cancer Inst. 1987;78(4):707-713.

39. Lamkanfi M, Kanneganti TD. Caspase-7: a protease involved in apoptosis and inflammation. Int $J$ Biochem Cell Biol. 2010;42 (1):21-24. doi:10.1016/j.biocel.2009.09.013

40. Tran S, DeGiovanni PJ, Piel B, Rai P. Cancer nanomedicine: a review of recent success in drug delivery. Clin Transl Med. 2017;6(1):44. doi:10.1186/s40169-017-0175-0

41. Tian J, Min Y, Rodgers Z, et al. Nanoparticle delivery of chemotherapy combination regimen improves the therapeutic efficacy in mouse models of lung cancer. Nanomedicine. 2017;13(3):1301-1307. doi:10.1016/j.nano.2016.11.007

\section{Publish your work in this journal}

OncoTargets and Therapy is an international, peer-reviewed, open access journal focusing on the pathological basis of all cancers, potential targets for therapy and treatment protocols employed to improve the management of cancer patients. The journal also focuses on the impact of management programs and new therapeutic agents and protocols on patient perspectives such as quality of life, adherence and satisfaction. The manuscript management system is completely online and includes a very quick and fair peer-review system, which is all easy to use. Visit http://www.dovepress.com/ testimonials.php to read real quotes from published authors. 